\title{
Estimating Central Bank Preferences under Commitment and Discretion
}

\author{
Gregory E. Givens \\ Assistant Professor of Economics \\ Department of Economics and Finance \\ Jennings A. Jones College of Business \\ Middle Tennessee State University \\ Murfreesboro, TN 37132 \\ ggivens@mtsu . edu
}

First Draft: June 2009

\begin{abstract}
This paper explains US macroeconomic outcomes with an empirical new-Keynesian model in which monetary policy minimizes the central bank's loss function. The presence of expectations in the model forms a well-known distinction between two modes of optimization, termed commitment and discretion. I estimate the model separately under each policy using maximum likelihood over the Volcker-Greenspan-Bernanke period. Comparisons of fit reveal that the data favor the specification with discretionary policy. Estimates of the loss function weights point to an excessive concern for interest rate smoothing in the commitment model but a more balanced concern relative to inflation and output stability in the discretionary model.
\end{abstract}

Keywords: Optimal Monetary Policy, Commitment, Discretion, Policy Preferences JEL Classification: E52, E58, E61, C32, C61 


\section{Introduction}

In macroeconomic models that embody rational expectations, optimal monetary policies are separated by a dichotomy known in the literature as commitment and discretion. Noted first by Kydland and Prescott (1977) and later by Barro and Gordon (1983), the key distinction between them can be traced to how private expectations are treated in the optimization problem. Under discretion, the central bank reoptimizes its loss function period-by-period, taking expectations of future policy actions as given in the determination of current policy. By contrast, commitment implies sequential implementation of a contingency plan that was chosen at an earlier date to be applied indefinitely. In the course of optimization, which occurs only once, the central bank internalizes the effect of its choices on private expectations.

This paper seeks to explain recent US macroeconomic outcomes in a modeling framework that accommodates either of these two styles of central bank behavior. The empirical analysis is motivated by two questions. First, given that the Federal Reserve sets interest rates in a deliberate fashion with specific goals in mind, can one infer from the data which method of optimization, commitment or discretion, is more reflective of actual policy management? Second, to what extent does consideration of the two policies yield different estimates of the parameters that describe the preferences of monetary policy?

Most empirical studies assume that interest rates are set according to simple rules of the type proposed by Taylor (1993). Such rules are appealing, the argument goes, because the coefficient estimates capture the systematic relationship between interest rates and other macroeconomic variables and, so, provide a reasonable description of the way central banks operate (e.g., Clarida, Galí, and Gertler, 2000). Discriminating commitment-like from discretionary policy in the data, however, requires that one drop this assumption in favor of an alternative setup that gives voice to the explicit loss minimization problem of the policymaker. As explained by McCallum (1999), optimization under both commitment and 
discretion involves the systematic response of policy to shifts in target variables. What distinguishes the two is whether private-sector forecasts are accounted for in the design of that policy response. Thus, interest rate rules, because they are estimated without reference to an underlying model of private behavior, are uninformative about the manner in which optimal policy is determined. McCallum (1999, p. 1489) reiterates this point when he remarks "that neither of these two modes of central bank behavior-rule-like [commitment] or discretionary - has as yet been firmly established as empirically relevant."

In light of these issues, this paper borrows from a recent literature that estimates the parameters of a macroeconomic model subject to the restriction that the interest rate equation minimizes the central bank's expected loss function (e.g., Ozlale, 2003; Favero and Rovelli, 2003; Dennis, 2006). Conditioning estimation on the assumption that policy is set optimally, whether it be in the form of commitment or discretion, enables one to obtain joint estimates of the structural parameters that describe private behavior and the loss function weights that identify the preferences of monetary policy. For the present study, the simultaneous approach to estimation also makes it possible to determine which of the two styles of optimization is more compatible with the data in terms of fit and what values the preference parameters must take for historical policy to have been the result of loss minimization.

The model used for estimation is a standard two-equation new-Keynesian structure that governs the evolution of output and inflation. It forms the constraints for the central bank's optimization problem. The stabilization goals are represented by a quadratic loss function that penalizes deviations of inflation and output from target as well as changes in the policy instrument, referred to as interest rate smoothing. The structural parameters together with the loss function weights are estimated using a maximum-likelihood procedure with quarterly US data spanning the Federal Reserve chairmanships of Volcker, Greenspan, and Bernanke. To examine how the stance of monetary policy affects the empirical findings, I estimate the model separately under commitment and discretion. I assess the fit of the two policies by 
computing the Bayesian information criterion and a related pseudo-posterior odds measure which summarizes the probability of a model given the data. Both statistics are useful for comparing fit because commitment and discretion are non-nested policies in the sense that each one imposes a different set of restrictions on the model.

Econometric results show that the parameter estimates are similar across both policy specifications with one exception. Under commitment, the weight on interest rate smoothing in the loss function is larger than the ones on either inflation or output. Discretionary policy, by contrast, lowers the smoothing penalty to a more plausible level, given the traditional focus among central banks on the other two objectives. The key factor driving this outcome is that commitment increases the volatility of the interest rate, forcing maximum likelihood to lift the weight on policy smoothing in an attempt to reconcile the model with the data. A comparison of model fit using Bayesian-motivated statistics reveals that discretionary policy provides a better overall description of the joint time series properties of the data.

\subsection{Related Literature}

There are several papers that estimate the structural parameters of a macroeconomic model subject to the auxiliary condition that monetary policy minimizes an explicit loss function. The earliest examples include Ozlale (2003) and Favero and Rovelli (2003), both of which estimate versions of the purely backward-looking model developed by Rudebusch and Svensson (1999). Employing different estimation strategies (Ozlale uses maximum likelihood whereas Favero and Rovelli use GMM), both papers find clear evidence of a structural break in the loss function weights after the appointment of Volcker to chairman of the Federal Reserve. Dennis (2006) uses a similar model to estimate the Fed's implicit inflation target during the Volcker-Greenspan period and to examine whether the assumption of optimal policy can be formally rejected by the data. The present study differs from this early literature in one important regard. The model used for estimation is forward-looking in that it emphasizes 
the role of private-sector expectations in the transmission of monetary policy. The presence of expectations draws a distinction between optimal policy under commitment and discretion that is altogether absent in the Rudebusch-Svensson model.

There is a recent literature that estimates central bank preferences in the context of forward-looking models. Dennis (2004) estimates a new-Keynesian model with discretionary policy and verifies that a structural break in the loss function parameters occurred at the time of Volcker's appointment. Applying the same optimality restrictions, Söderström, Söderlind, and Vredin (2005) examine whether a loss function and a structural model can be jointly parameterized to match the broad moments in the US data. Castelnuovo (2006) demonstrates that adding forward-looking terms to a model with discretionary policy reduces the weight on interest rate smoothing needed to fit the data. Salemi (2006) examines the case of commitment to an optimized Taylor-type rule and concludes that the Fed placed greater emphasis on stabilizing inflation after 1980. Givens and Salemi (2008) employ the same model but focus instead on testing the efficiency of a proposed GMM strategy for joint estimation. Finally, Ilbas (2008a) uses Bayesian methods to estimate the euro-area model of Smets and Wouters (2003) conditional on the assumption that policy is set under full commitment.

While the papers in this literature deal with a variety of specific issues, they all share one aspect in common. Each paper makes an a priori assumption about the nature of monetary policy by considering only one of the two possible styles of central bank optimization. In this study, by contrast, I take a step back and attempt to infer from the data which style is more empirically relevant. To my knowledge, this is the first paper that systematically compares the empirical effects of commitment and discretion by estimating the two policies side-by-side. 


\section{A Small Empirical Model of the US Economy}

\subsection{The Policy Constraints}

The constraints belong to a class of new-Keynesian models that have been applied extensively in the study of optimal monetary policy. Rotemberg and Woodford (1997) and McCallum and Nelson (1999) demonstrate how to derive a purely forward-looking new-Keynesian structure from an underlying model of optimizing households and firms. Its policy implications are examined in detail by Clarida, Galí, and Gertler (1999). The version used in this paper features additional backward-looking elements meant to capture the inertial qualities of the data (e.g., Fuhrer and Moore, 1995; Fuhrer, 1997).

Denote $y_{t}$ the output gap, the log deviation of real output from potential, and let $\pi_{t}$ be the inflation rate between dates $t-1$ and $t$. The output gap is described by an IS equation

$$
y_{t}=\phi E_{t} y_{t+1}+(1-\phi)\left(\beta y_{t-1}+(1-\beta) y_{t-2}\right)-\sigma\left(i_{t}-E_{t} \pi_{t+1}\right)+u_{y, t}
$$

where $i_{t}$ is the nominal interest rate, and $u_{y, t}$ is a mean-zero, serially uncorrelated demand shock with variance $\sigma_{y}^{2}$. The parameter $\sigma>0$ is the intertemporal elasticity of substitution in consumption, and $\phi \in[0,1]$ measures the degree of forward-looking behavior in household spending decisions. The presence of lagged output gaps in the IS equation whenever $\phi<1$ can be justified on the basis of habit formation in consumption (e.g., Fuhrer, 2000).

The inflation rate is governed by an expectations-augmented Phillips curve

$$
\pi_{t}=\alpha E_{t} \pi_{t+1}+(1-\alpha) \pi_{t-1}+\kappa y_{t}+u_{\pi, t}
$$

where $u_{\pi, t}$ is a mean-zero, serially uncorrelated supply shock with variance $\sigma_{\pi}^{2}$. I allow for nonzero correlation between supply and demand shocks and denote their covariance by $\sigma_{y \pi}$. 
The parameter $\alpha \in[0,1]$ measures the extent to which monopolistically competitive firms are forward looking in their pricing decisions. The slope coefficient $\kappa>0$ carries information regarding the frequency of optimal price adjustments. Greater nominal rigidity, meaning less frequent adjustments, implies a smaller value of $\kappa$. To account for inflation persistence, the Phillips curve includes a lagged term whenever $\alpha<1$. Backward-looking components can be motivated in theory by the presence of rule-of-thumb price setters (e.g., Galí and Gertler, 1999) or non-optimizing firms that index to past inflation (e.g., Smets and Wouters, 2003). The fact that the coefficients on lagged and future inflation sum to one implies that the model is consistent with the view that monetary policy has no long-run effect on output.

\subsection{The Loss Function}

The central bank determines the optimal path of the nominal interest rate in order to minimize an intertemporal loss function

$$
\mathbb{L}_{t}=E_{t}(1-\delta) \sum_{j=0}^{\infty} \delta^{j}\left\{\pi_{t+j}^{2}+\lambda_{y} y_{t+j}^{2}+\lambda_{\Delta i}\left(i_{t+j}-i_{t+j-1}\right)^{2}\right\}
$$

where the discount factor $\delta \in(0,1)$ and $\lambda_{y}, \lambda_{\Delta i} \geq 0$. The first two terms penalize squared deviations of inflation and output from their respective targets. I assume that the inflation target is constant over time and, without loss of generality, is normalized to zero. The target for output is the potential level. ${ }^{1}$ The third term penalizes deviations of the interest rate from its previous level and is interpreted as an interest rate smoothing incentive for the policymaker. The weights $\lambda_{y}$ and $\lambda_{\Delta i}$ measure the relative preference for stabilizing output and the interest rate smoothing argument. The weight on inflation is normalized to one.

The loss function (3) is an appealing way to characterize central bank preferences for a

\footnotetext{
${ }^{1}$ The model is equivalent to one that explicitly accounts for a nonzero inflation target, but where the variables appearing in (1) and (2) are written as deviations from target values. The output target is still the potential level, and the nominal interest rate target is the sum of the inflation target and the steady-state real interest rate. See Dennis (2004) for an illustration of this equivalency.
} 
variety of reasons. First, parameterized versions of (3) are commonly used to evaluate alternative monetary policies (e.g., Rudebusch and Svensson, 1999; Levin and Williams, 2003). Second, Svensson (1999) argues that the main objectives of a flexible inflation-targeting central bank can be described with a loss function that jointly stabilizes inflation and a measure of real activity. This point is particularly relevant because many have argued that the Federal Reserve under Volcker and Greenspan employed a policy framework that closely resembles inflation targeting (e.g., Bernanke and Mishkin, 1997; Goodfriend, 2003). Third, Woodford (2002) shows that under certain conditions, loss functions like (3) (with $\lambda_{\Delta i}=0$ ) correspond to a second-order Taylor series expansion of the representative consumer's expected utility.

Although difficult to justify in theory, including an interest rate smoothing term is empirically compelling because it helps capture the degree of policy gradualism observed in the data. There are many explanations for why gradualism is desirable. Woodford (2003b) shows that in forward-looking models, interest rate inertia is a defining feature of an optimal inflation-targeting rule. With parameter uncertainty, Brainard (1967) demonstrates that policy interventions should be cautious so as to avoid excess volatility resulting from misperceptions of the model. Orphanides (2003) argues that similar caution is advisable when there is uncertainty regarding the accuracy of incoming data. Finally, Lowe and Ellis (1997) point out that such preferences may reflect a concern for financial market stability.

\subsection{Optimal Monetary Policy}

To compute optimal policies, I stack the constraints in matrix form

$$
\left[\begin{array}{c}
X_{t+1} \\
\Omega E_{t} x_{t+1}
\end{array}\right]=A\left[\begin{array}{c}
X_{t} \\
x_{t}
\end{array}\right]+B i_{t}+\left[\begin{array}{c}
\Gamma u_{t+1} \\
0
\end{array}\right]
$$


where $X_{t}=\left[\begin{array}{llllll}u_{y, t} & u_{\pi, t} & y_{t-1} & y_{t-2} & \pi_{t-1} & i_{t-1}\end{array}\right]^{\prime}$ is a vector of predetermined variables, $x_{t}=\left[\begin{array}{ll}y_{t} & \pi_{t}\end{array}\right]^{\prime}$ is a vector of forward-looking variables, and $u_{t+1}=\left[\begin{array}{ll}u_{y, t+1} & u_{\pi, t+1}\end{array}\right]^{\prime}$ is a vector of innovations with covariance matrix $\Sigma_{u u}$. Structural parameters appear as elements of the matrices $\Omega, A$, and $B$, and $\Gamma$ is a selector matrix. I use the methods described by Söderlind (1999) to solve for the equilibrium dynamics of the model.

The central bank selects the path of the nominal interest rate to minimize (3) subject to (4). Because the model is forward looking, policymakers face constraints that depend on expectations about the current and future course of monetary policy. Under commitment, the central bank announces a state-contingent plan for the interest rate that is to be applied at all future dates. In the setting of policy it treats private-sector forecasts as endogenous, thereby internalizing the effect of its choices on private behavior. The outcome is an optimal equilibrium that makes efficient use of expectations to achieve the goals embodied by the loss function. ${ }^{2}$ The resulting dynamics are given by

$$
\begin{aligned}
{\left[\begin{array}{l}
X_{t+1} \\
\psi_{t+1}
\end{array}\right] } & =M_{c}\left[\begin{array}{l}
X_{t} \\
\psi_{t}
\end{array}\right]+\left[\begin{array}{c}
\Gamma u_{t+1} \\
0
\end{array}\right], \\
{\left[\begin{array}{c}
x_{t} \\
i_{t}
\end{array}\right] } & =G_{c}\left[\begin{array}{l}
X_{t} \\
\psi_{t}
\end{array}\right],
\end{aligned}
$$

where $\psi_{t}$ is a vector of multipliers associated with the lower block of (4). Woodford (2003a, Ch. 7) explains that the multipliers capture the effects of the anticipation at all previous dates of current policy actions. The dependence upon $\psi_{t}$ constrains the central bank to honor past commitments every period, making the interest rate equation in (6) history dependent.

Under discretion, the central bank is not bound by promises made in the past. At each

\footnotetext{
${ }^{2}$ Although the commitment policy is ex ante optimal, policymakers face an ex post incentive to abandon it (e.g., Kydland and Prescott, 1977). I show how to deal with the time-inconsistent nature of the commitment equilibrium as an empirical matter in the next section.
} 
point in time, it evaluates the current state of the economy and sets policy optimally on the basis of this assessment alone, with no forward commitment about subsequent actions. Private forecasts of future policy choices are taken as given in the setting of interest rates. Macroeconomic outcomes are only optimal in a constrained sense because the central bank, through sequential reoptimization, fails to harness expectations in a way that advances its stabilization goals. The dynamics resulting from the discretion equilibrium are given by

$$
\begin{aligned}
X_{t+1} & =M_{d} X_{t}+\Gamma u_{t+1}, \\
{\left[\begin{array}{c}
x_{t} \\
i_{t}
\end{array}\right] } & =G_{d} X_{t} .
\end{aligned}
$$

In contrast to commitment, the policy equation in (8) is entirely forward looking, as the interest rate depends only on the current outlook for the predetermined variables.

\section{Estimation Strategy}

The recursive equilibrium under commitment or discretion takes the form an empirical statespace model that can be estimated with maximum likelihood using the Kalman filtering algorithms described in Hamilton (1994, Ch. 13). The state equation is

$$
\xi_{t+1}=F \xi_{t}+\tilde{\Gamma} u_{t+1},
$$

where $\xi_{t} \in\left\{\left[X_{t}^{\prime} \psi_{t}^{\prime}\right]^{\prime}, X_{t}\right\}, F \in\left\{M_{c}, M_{d}\right\}$, and $\tilde{\Gamma} \in\left\{\left[\Gamma^{\prime} 0\right]^{\prime}, \Gamma\right\}$. The observation equation is

$$
\left[\begin{array}{c}
y_{t}^{o} \\
\pi_{t}^{o} \\
i_{t}^{o}
\end{array}\right]=H \xi_{t}+\left[\begin{array}{c}
0 \\
0 \\
v_{i, t}
\end{array}\right]
$$


where $\left\{y_{t}^{o}, \pi_{t}^{o}, i_{t}^{o}\right\}_{t=1}^{T}$ denotes the observed series for the output gap, inflation, and the nominal interest rate, and $H \in\left\{G_{c}, G_{d}\right\}$. The stochastic variable $v_{i, t}$ is a mean-zero, serially uncorrelated shock to the observed interest rate. Its variance $\sigma_{i}^{2}$ can be interpreted as a measure of the discrepancy between the optimal policy implied by the model and the actual interest rate in the sample. With data on three variables, adding $v_{i, t}$ also circumvents the stochastic singularity problem emphasized by Ingram, Kocherlakota, and Savin (1994).

The structural parameters are estimated with quarterly US data over the period 1982:Q1 - 2008:Q4. ${ }^{3}$ The output gap is the log deviation of real GDP from potential GDP as constructed by the Congressional Budget Office. Inflation is the first difference of the log of the GDP implicit price deflator expressed at an annual rate. The nominal interest rate is the annual percentage yield on 3-month Treasury bills. I de-mean the the inflation and interest rate series to make them conformable with the model. De-meaning implies that the target values (unmodeled) correspond to the sample averages. This assumption is reasonable because the goals are to examine model fit and identify loss function weights under opposing policy specifications rather than uncover estimates of the Fed's implicit target levels. ${ }^{4}$ Moreover, de-meaning ensures that the underlying targets will be the same for either policy.

Application of the Kalman filter typically begins with a date-0 estimate of the initial state vector, call it $\hat{\xi}_{1 \mid 0}$, equal to its long-run mean. The mean value implied by (9) is zero. This is problematic for estimation under commitment because $\xi_{t}$ contains the multipliers associated with the forward-looking variables in (4). Starting the recursion with $\psi_{t}=0$ implies that the central bank reneges on previous commitments in the initial period, making the equilibrium time inconsistent. For the purpose of estimation, I assume that the Fed has announced its contingency rule at some point that predates the sample. It follows that the economy's initial evolution must be consistent with the policy that prevails at all dates

\footnotetext{
${ }^{3}$ Following Dennis (2006), I begin the sample in 1982:Q1 in order to exclude the period when the Federal Reserve's operating procedure focused on targeting the quantity of non-borrowed reserves.

${ }^{4}$ The same approach has been used by Ozlale (2003), Söderström et al. (2005), and Castelnuovo (2006).
} 
after the starting period. This is equivalent to adopting an equilibrium concept that relates closely to what Woodford (2003a) calls the optimal policy from a "timeless perspective."

To prevent the central bank from arbitrarily deviating from the commitment equilibrium at the beginning of the sample requires selecting a nonzero value for $\hat{\xi}_{1 \mid 0}$. Although the multipliers are unobservable, I can make an informed decision about their starting values by using the output from the Kalman filter. Specifically, I estimate the model in a first stage by setting $\hat{\xi}_{1 \mid 0}^{(1)}=0$. I then apply the Kalman filter to generate a sequence of date- $t$ updated projections of the state, which I denote $\left\{\hat{\xi}_{t \mid t}^{(1)}\right\}_{t=1}^{T}$. Next, I re-estimate the model using as the initial state the sample average of forecasts computed in the previous step, that is, $\hat{\xi}_{1 \mid 0}^{(2)}=(1 / T) \sum_{t=1}^{T} \hat{\xi}_{t \mid t}^{(1)}$. I repeat this process until the initial state equals the mean value of the sequence of forecasts produced by the Kalman filter, or $\hat{\xi}_{1 \mid 0}^{(i+1)}=\hat{\xi}_{1 \mid 0}^{(i)}$. For estimation under both commitment and discretion, convergence was obtained in less than 10 iterations. $^{5}$

\section{Empirical Results}

\subsection{Maximum Likelihood Estimates}

Table 1 displays the point estimates and standard errors of the model's 11 structural parameters. ${ }^{6}$ Panel A presents estimates for the case of optimal commitment, and panel B presents estimates for discretion. The standard errors are computed by taking the square roots of the diagonal elements of the information matrix, obtained by inverting the matrix of second derivatives of the maximized log-likelihood function.

There are numerous similarities in the estimates across policies. Looking first at the

\footnotetext{
${ }^{5}$ An alternative strategy adopted by Ilbas (2008a) is to partition the sample to include an initialization period that precedes estimation. She finds that a presample period of 20 quarters is sufficient to eliminate any effects on parameter estimates of setting the multipliers equal to zero in the initial period. Estimating the model in this paper using a presample initialization period produced results similar to the ones reported using the iterative approach described above.

${ }^{6}$ I fix the central bank's discount factor $\delta=0.99$ prior to estimation. Stress tests showed that the remaining estimates are not overly sensitive to variations in this parameter.
} 
Table 1: Maximum Likelihood Estimates

\begin{tabular}{lrrrrrr}
\hline \hline Parameter & \multicolumn{2}{c}{ A. Commitment } & \multicolumn{2}{c}{ B. Discretion } & \multicolumn{2}{c}{ C. Unrestricted } \\
& Estimate & Std. Error & Estimate & Std. Error & Estimate & Std. Error \\
\hline$\sigma_{y}$ & 0.2482 & 0.0197 & 0.2065 & 0.0141 & 0.2197 & 0.0169 \\
$\sigma_{\pi}$ & 0.5745 & 0.0395 & 0.6108 & 0.0354 & 0.6125 & 0.0371 \\
$\sigma_{y \pi}$ & -0.0381 & 0.0145 & -0.0352 & 0.0124 & -0.0227 & 0.0140 \\
$\sigma_{i}$ & 0.9274 & 0.0638 & 0.9403 & 0.0459 & 0.9210 & 0.0614 \\
$\lambda_{y}$ & 0.1351 & 0.0576 & 0.0987 & 0.0430 & - & - \\
$\lambda_{\Delta i}$ & 2.5581 & 0.1827 & 0.0579 & 0.0260 & - & - \\
$\phi$ & 0.3286 & 0.0099 & 0.3747 & 0.0050 & 0.4126 & 0.0125 \\
$\beta$ & 1.5153 & 0.0100 & 1.4483 & 0.0037 & 1.3366 & 0.0382 \\
$\sigma$ & 0.0089 & 0.0027 & 0.0002 & $6.49 \mathrm{e}-5$ & 0.0012 & 0.0015 \\
$\alpha$ & 0.4927 & 0.0070 & 0.6162 & 0.0207 & 0.6291 & 0.0246 \\
$\kappa$ & 0.0045 & 0.0016 & 0.0047 & 0.0025 & $4.58 \mathrm{e}-9$ & $5.72 \mathrm{e}-20$ \\
\hline \hline
\end{tabular}

covariances, estimates of $\sigma_{y}$ and $\sigma_{\pi}$ indicate that supply shocks are more than twice as volatile as demand shocks. Estimates of $\sigma_{i}$ suggest that the disparity between observed interest rates and the optimal ones implied by the model are largely invariant to the two modes of central bank behavior.

Turning next to the IS and Phillips curves, estimates of $\phi$ and $\alpha$ indicate that forward and backward-looking terms are important for output and inflation dynamics. The estimate of $\phi$ is close to one-third under commitment and about 0.37 under discretion. Both values fall in the neighborhood of estimates reported by Fuhrer and Rudebusch (2004) and Lindé (2005). The estimates of $\alpha$ are 0.49 and 0.62, echoing the findings of Roberts (2005) and Kiley (2007). Estimates of $\kappa$, the output gap elasticity of inflation, are small but within the range typical of the literature. Values of $\kappa$ near zero are evidence of long duration of price stickiness or large strategic complementarities accompanied by modest nominal rigidities. ${ }^{7}$

Concerning the loss function, estimates of $\lambda_{y}$ point to a small weight on output gap stability relative to inflation. There is some empirical support for the notion that the Fed has concern for output only to the extent that it helps control inflation. Salemi (2006),

\footnotetext{
${ }^{7}$ See Woodford (2003a, Ch. 3) for details.
} 
Dennis (2006), and Givens and Salemi (2008), for example, find no evidence of a distinct output gap stabilization goal in the loss function. It would be wrong, however, to conclude that output stability is unimportant in this model. A Wald test of the null hypothesis that $\lambda_{y}=0$, formed by squaring the ratio of the point estimate to its standard error, is rejected at normal significance levels under both policies. This result parallels Favero and Rovelli (2003), Ozlale (2003), and Ilbas (2008b) who find that the weight on output volatility is quantitatively small but statistically significant.

The data tells a very different story about the importance of interest rate smoothing depending on the specification of policy. Under commitment the estimate of $\lambda_{\Delta i}=2.5581$, indicating that central bank attitudes are chiefly concerned with smoothing interest rates followed by inflation and then output gap stability. Under discretion, however, the estimate of $\lambda_{\Delta i}=0.0579$, placing the interest rate objective just below output in the central bank's ordering of policy goals. The smoothing penalty seems far more palatable under discretion in light of the consensus view that monetary policy has traditionally placed more emphasis on inflation and output in accordance with the so-called "dual mandate" of the Federal Reserve (e.g., Mishkin, 2007). Rudebusch (2006) is similarly critical of loss functions that put a large weight on $\left(i_{t}-i_{t-1}\right)^{2}$ because it is inconsistent with evidence on expected future monetary policy embedded in the term structure. I return to the issue of why inferences about the role of interest rate smoothing are so different across the two policies in a later section.

\subsection{Model Comparison}

In this section I assess the empirical performance of commitment and discretion in two different ways. First, I calculate a number of second moments implied by the estimated models and compare them to ones obtained from the data. Classical estimation, however, does not focus exclusively on matching this limited set of moments, so I also compare the models by appealing to a broad measure of fit provided through the likelihood function. 
Table 2: Standard Deviations

\begin{tabular}{lcrr}
\hline \hline Variable & Data & Commitment & Discretion \\
\hline Inflation & 1.0822 & 2.2140 & 1.2298 \\
Output Gap & 2.2506 & 4.5958 & 2.7194 \\
Nominal Interest Rate & 2.4144 & 3.7923 & 3.0239 \\
\hline \hline
\end{tabular}

Notes: Standard deviations are multiplied by 100.

Specifically, I compute the Bayesian information criterion for both policies, and from that a posterior odds measure that reveals the probability of a particular model given the data.

Table 2 presents the standard deviations of inflation, the output gap, and the nominal interest rate as implied by the data and the models. The model with discretionary policy does a better job of accounting for the standard deviations of all three variables. The volatility of inflation, in particular, is only slightly larger than the realized volatility in the data. Under commitment, however, the model overstates inflation and output gap volatility.

Figure 1 plots the vector autocorrelation functions for the same variables. As in Fuhrer and Moore (1995), the autocorrelations for the data are computed from an unrestricted, fourth-order vector autoregression. In most cases, the unconstrained model explains well the pattern of cross correlations regardless of the policy design. Both policies, for example, deliver substantial output gap persistence as measured by the correlations between current and lagged output gaps. The half-life of this autocorrelation is about 5 quarters. A similar result applies to the persistence observed in the nominal interest rate. The models also match closely the positive and declining lead-lag relationship between inflation and the interest rate.

There are two areas where discretionary policy generates a more visible improvement in fit. The first is the degree of inflation persistence reflected in the autocorrelation function for inflation. The half-life of this function is 2 quarters under discretion but about 5 quarters under commitment. Discretionary policy also improves the accuracy of the cross correlations between the output gap and inflation. In the absence of commitment, the model correctly 
Table 3: Model Comparison

\begin{tabular}{lrrrr}
\hline \hline Model & Log likelihood & BIC & $\begin{array}{r}\text { Pseudo-odds } \\
(z=2)\end{array}$ & $\begin{array}{r}\text { Pseudo-odds } \\
(z=3)\end{array}$ \\
\hline Commitment & -387.7724 & -413.4729 & 0.0003 & 0.0002 \\
Discretion & -379.6072 & -405.3078 & 0.9997 & 0.7489 \\
Unrestricted & -371.3551 & -406.4013 & - & 0.2509 \\
\hline \hline
\end{tabular}

Notes: BIC refers to the Bayesian information criterion. The pseudo-odds statistic measures the ex post probability of a model $j$ and is defined as $\rho(j)=\exp (B I C(j)) / \sum_{h=1}^{z} \exp (B I C(h))$, where $z$ is the number of distinct models under consideration.

predicts the sign and magnitude of this relationship at leads and lags of up to one year.

Another way to evaluate model fit is by computing the Bayesian information criterion (BIC). The BIC is a consistent model-selection criterion that penalizes log likelihood by an amount that is increasing in the number of estimated parameters. In contrast to likelihood ratio tests, it can be used to compare a class of parametric models that are non-nested like the ones examined in this paper. The BIC for model $j$ is

$$
B I C(j)=\mathcal{L}(j)-\frac{N(j)}{2} \ln (T)
$$

where $\mathcal{L}(j)$ is the maximized value of $\log$ likelihood, $N(j)$ is the number of parameters in model $j$, and $T$ is the sample size. The BIC can also be used to construct a pseudo-posterior odds measure that provides the data-determined probability of a model. The pseudo-odds measure for model $j$ is

$$
\rho(j)=\frac{\exp (B I C(j))}{\sum_{h=1}^{z} \exp (B I C(h))},
$$

where $z$ is the number of different models under consideration. ${ }^{8}$ Although it holds the same information as the BIC, the pseudo-odds statistic is useful because it translates the likelihood function into a measure of the relative odds of competing models given the available data.

\footnotetext{
${ }^{8}$ Recent studies that utilize the BIC include Brock, Durlauf, and West (2003) and Kiley (2007).
} 
Table 3 reports the value of log likelihood, the BIC, and the pseudo-posterior odds measure for the models under commitment and discretion. ${ }^{9}$ Log likelihood and the BIC are substantially larger for the case of discretion and, consequently, the pseudo-odds measure points to a very small ex post probability of the commitment model.

It is clear that discretionary policy outperforms commitment according to several objective measures of empirical fit. But does it still perform well relative to a wider class of models that do not condition estimation on the assumption that monetary policy is set optimally? To address this question, I re-estimate (1) and (2) jointly with an equation for the interest rate that places no restrictions on the reduced-form coefficients appearing in the third row of $G_{d}$. This specification allows policy to respond freely to every element in the state vector. Maximum likelihood estimates of the parameters in (1) and (2) are reported in panel $\mathrm{C}$ of Table 1 . Most of the estimates are close to the ones obtained under discretion. The exception is $\kappa$, which is considerably smaller in the unrestricted model. The estimated interest rate equation (with standard errors in parentheses) is

$$
i_{t}=\underset{(0.0605)}{1.8631} \varepsilon_{y, t}+\underset{(0.0653)}{0.1387} \varepsilon_{\pi, t}+\underset{(0.0795)}{0.5539} y_{t-1}-\underset{(0.0818)}{0.4841} y_{t-2}+\underset{(0.0320)}{0.2983} \pi_{t-1}+\underset{(0.0183)}{0.8821} i_{t-1} .
$$

For comparison, the reduced-form interest rate equation in the discretionary model is

$$
i_{t}=\underset{(0.1919)}{2.3612} \varepsilon_{y, t}+\underset{(0.0448)}{0.5099} \varepsilon_{\pi, t}+\underset{(0.0658)}{0.7088} y_{t-1}-\underset{(0.0581)}{0.6618} y_{t-2}+\underset{(0.0230)}{0.1957 \pi_{t-1}}+\underset{(0.0100)}{0.9017 i_{t-1}}
$$

where standard errors are obtained using the delta method. There are several qualitative similarities between the two policy equations. Both call for countercyclical responses to demand and supply shocks, further contractionary adjustments to lagged output-gap growth and inflation, and substantial interest rate inertia. Quantitatively, however, the coefficients

\footnotetext{
${ }^{9}$ As a criterion for selecting between commitment and discretion, the BIC is equivalent to maximum likelihood because the number of parameters are equal in the two models.
} 
are somewhat larger under discretion except for the response to lagged inflation.

The unrestricted model has 15 free parameters, 9 structural parameters plus 6 policy rule coefficients. The restricted model contains only the 9 structural parameters and 2 loss function weights, meaning that discretionary policy implies a total of 4 restrictions on the model. I conduct a likelihood ratio test of these restrictions by doubling the difference between the log likelihood values reported in Table 3. The relevant chi-square statistic is 16.504 with a $p$-value less than 0.01 . The restrictions imposed by optimal discretion, therefore, weaken the model's ability to fit the data according to this test.

Evidence of model fit provided by the BIC, however, points to a different conclusion about the validity of the optimal policy restrictions. Because it penalizes over-parameterized models, the BIC for the case of discretion is larger than its unrestricted counterpart, and both are larger than the one for commitment. The pseudo-posterior odds measures indicate the probability of the discretionary model is about 75 percent and the probability of the unrestricted model is 25 percent. The probability of the commitment model is near zero.

\subsection{The Role of Interest Rate Smoothing}

Inferences about the role of interest rate smoothing as an independent goal of policy vary greatly depending on the mode of central bank optimization. Estimates under commitment suggest that it is the most important objective in the loss function, while discretion implies the exact opposite. In this section I provide some intuition for why maximum likelihood produces such contradictory findings.

Figure 2 graphs the impulse responses to demand and supply shocks for two different versions of the model. The first version corresponds to the estimated model under discretion. The second version takes the same parameters (including loss function weights) but has the central bank minimize loss under commitment. The ensuing differences in model dynamics are, therefore, driven entirely by the procedure for setting interest rates. As expected, 
commitment leads to more stable dynamics of the output gap and inflation. A demand shock generates plausible "hump-shaped" movements in both variables, but the amplitude and persistence of the responses are smaller under commitment. A supply shock also raises inflation, but the steady-state reversion is more sluggish under discretion. It is easy to see how the central bank achieves greater stability by examining the response of the interest rate. By committing in advance to maintain high interest rates for an extended period, policymakers reduce expectations of future output gaps and inflation and, consequently, dampen the adjustment of those variables in the current period.

The problem with the commitment outcome from an empirical perspective is that it implies a level of interest rate volatility that is severely at odds with the data. Any datafitting exercise will naturally seek parameter values that drive down this volatility. Figure 3 illustrates some of the key tradeoffs faced by maximum likelihood when locating the estimate of $\lambda_{\Delta i}$. The figures plot the standard deviations of inflation, the output gap, and the interest rate for a range of values of $\lambda_{\Delta i}$, holding the other parameters fixed at their point estimates. The left panel graphs the functions implied by the model under discretion, and the right panel corresponds to commitment. The vertical lines indicate the estimated values of $\lambda_{\Delta i}$, and the crosses identify the moments in the sample.

In the case of discretion, raising $\lambda_{\Delta i}$ lowers the standard deviation of the interest rate but has surprisingly little effect on output and inflation. Most of the reduction occurs at small values of $\lambda_{\Delta i}$. As it approaches zero, the interest rate becomes extremely volatile, whereas values above 0.09 drive the standard deviation below historical levels. Under commitment, a larger weight on interest rate smoothing is needed to reconcile the model with the data. For values of $\lambda_{\Delta i}$ near the discretionary estimate, the interest rate is more than twice as volatile as the actual series. As $\lambda_{\Delta i}$ rises, the standard deviation of the interest rate falls, but those of the output gap and inflation increase. The pace at which interest rate volatility declines, however, is relatively slow. As a result, maximum likelihood compromises between 
competing moments by selecting a large value of $\lambda_{\Delta i}$ at which the standard deviations of all three variables exceed their sample counterparts by nontrivial amounts.

It should be noted that the increased weight on interest rate smoothing is not the only reason why inflation and output gap volatility are too high in the commitment model. As Figure 3 makes clear, the standard deviations of both variables are larger than those from the data even when $\lambda_{\Delta i}=0$. The explanation for this finding is straightforward. During the course of estimation, maximum likelihood concentrates on an area of the parameter space that strikes a balance between all of the moments embodied by the likelihood function. It turns out that the relevant area is one that implies uniformly less forward-looking behavior in the IS and Phillips curves. All else equal, smaller estimates of $\phi$ and $\alpha$ boost the volatility and persistence of the output gap and inflation. Söderström et al. (2005) demonstrate the same property in a related new-Keynesian model with optimal monetary policy.

Figure 4 illustrates this point by graphing the impulse response functions for the models under commitment and discretion. In contrast to Figure 2, changes in dynamics are now driven by the policy specification as well as variation in the structural parameters. As a consequence of the large estimate of $\lambda_{\Delta i}$, the interest rate response to demand and supply shocks under commitment is much closer to the adjustment paths observed in the discretionary case. In particular, commitment no longer generates chronic departures of the interest rate from its long-run level. However, greater concern for policy smoothing together with smaller values of $\phi$ and $\alpha$ raises output and inflation volatility. The peak effect of a demand shock on inflation is twice as large in the commitment model and occurs three quarters later than discretion. After a supply shock, inflation expands in both models, but the adjustment back to steady state is more gradual under commitment. The responses of the output gap exhibit a similar pattern of increased volatility when moving from discretion to commitment. 


\section{Counterfactual Analysis}

The evidence suggests that macroeconomic outcomes over the sample period are more consistent with the notion that the Federal Reserve set policy under discretion rather than commitment. In light of this analysis, I conduct an interesting counterfactual experiment in this section. Assuming that historical policy actions were the result of discretionary optimization, how much better off would outcomes have been had the Fed precommitted to an optimal rule? To answer this question, I perform counterfactual simulations of the estimated discretionary model to ascertain how the economy might have evolved under commitment.

Figure 5 displays the actual series for inflation, the output gap, and the interest rate and the paths those variables would have taken had the Fed adopted the commitment policy from 1982:Q1 to 2008:Q4. To produce the counterfactual data, I use the fixed interval Kalman smoother described by de Jong (1989) to estimate the history of shocks implied by the model with discretionary policy. ${ }^{10}$ I then reinsert those shocks back into the model, holding the parameters fixed (including loss function weights) but with the policy shifted to commitment.

Simulations reveal that the interest rate path would have been different under commitment. Rates would have fallen rapidly during the 1980s, bottoming out at 1.16 percent in 1986:Q4 before reaching a high of 7.46 percent in 1990:Q4 and staying close to historical levels for the rest of the decade. After peaking at 10.62 percent in 2000:Q4, the interest rate would have tumbled for the duration of the sample. Overall, the volatility of the simulated path is much larger than what actually transpired. The maximum difference between the counterfactual and observed series is 6.59 percentage points, occurring in 2002:Q4.

Despite very different policy behavior at times, the paths of inflation and the output gap would have been remarkably similar to historical outcomes. Inflation would have been slightly smaller before 1995:Q1 under commitment and slightly larger thereafter. The biggest

\footnotetext{
${ }^{10}$ The smoothed estimates of the shocks reflect information contained in the full set of data.
} 
Table 4: Counterfactual Losses under Discretion

\begin{tabular}{lrrrrrrc}
\hline \hline Policy & $\operatorname{Var}(\pi)$ & $\operatorname{Var}(y)$ & $\operatorname{Var}(\Delta i)$ & $\operatorname{Var}(i)$ & Loss & $\pi^{e q}$ & $y^{e q}$ \\
\hline A. No Zero Lower Bound & & & & & & & \\
Discretion & 1.5124 & 7.3958 & 2.3421 & 9.1447 & 2.2148 & 0.4392 & 1.3978 \\
Commitment & 1.3886 & 6.7863 & 2.4175 & 66.7330 & 2.0219 & - & - \\
& & & & & & & \\
B. Zero Lower Bound Imposed & & & & & & \\
Discretion & 1.5124 & 7.3958 & 2.3421 & 9.1447 & 2.2148 & 0.3665 & 1.1665 \\
Commitment & 1.4045 & 7.2425 & 1.8775 & 14.5811 & 2.0805 & - & - \\
\hline \hline
\end{tabular}

Notes: The table reports the variances of inflation $\pi$, the output gap $y$, and the interest rate in first differences $\Delta i$ and levels $i$, and the value of loss under discretion and commitment. The loss differential is also reported in terms of an inflation equivalent $\pi^{e q}$ and an output gap equivalent $y^{e q}$. Panel A contains results for the case with no zero bound constraint. Panel B contains results for the case in which the zero bound restriction is imposed by amending the loss function to include a suitable weight on the variance of the interest rate.

gap between the two series is only 0.53 percentage points in 1990:Q2. The output gap also would have been somewhat lower in the late 1980s and early 1990s but a bit higher in the second half of the 1990s and again after 2002:Q1.

Although useful for historical comparisons, counterfactual simulations do not easily translate into a single measure that quantifies the cumulative losses associated with one policy relative to another. For this purpose I follow Jensen (2002) and Dennis and Söderström (2006) and compute the "inflation equivalent" for the estimated model, interpreted as the permanent increase in inflation from target that in terms of central bank loss is equivalent to moving from the commitment equilibrium to discretion. From (3), the inflation equivalent can be calculated as $\pi^{e q}=\sqrt{\mathbb{L}_{d}-\mathbb{L}_{c}}$, where $\mathbb{L}_{d}$ and $\mathbb{L}_{c}$ are the values of loss under discretion and commitment, respectively. ${ }^{11}$ A similar quantity measured in terms of lost output (an output gap equivalent) is given by $y^{e q}=\pi^{e q} / \sqrt{\lambda_{y}}$.

Table 4 (panel A) reports loss under both policies as well as the inflation and output gap equivalents from discretion. For comparison, it also presents the variances of inflation,

\footnotetext{
${ }^{11} \mathrm{~A}$ permanent inflation rate of $\pi^{e q}$ yields a loss equal to $(1-\delta) \sum_{j=0}^{\infty} \delta^{j} \pi^{e q^{2}}=\pi^{e q^{2}}$. The inflation equivalent, therefore, satisfies $\mathbb{L}_{c}+\pi^{e q^{2}}=\mathbb{L}_{d}$.
} 
the output gap, and the interest rate in first differences and levels. Moving from discretion to commitment leads to small reductions in the variances of inflation and the output gap and a comparable increase in the variance of interest rate differences. The variance of the interest rate in levels, however, is considerably larger under commitment. The value of loss is about 10 percent higher under discretion, a gap that is equivalent to a permanent increase in inflation of 0.4392 percentage points or an output gap of 1.3978 percentage points.

The modest improvement in macroeconomic stabilization overstates the true gains that commitment could have achieved once one considers that such a policy would not have been operational. The reason is because commitment implies such a high volatility of the interest rate that violations of the zero bound would have been frequent. Indeed, Figure 5 reveals that the simulated path becomes negative in 2004:Q4 and continues to decline through 2008.

To reassess the gains from commitment while respecting the presence of a zero bound, I follow Woodford (2003a, Ch. 6) in approximating the effects of this constraint by modifying the loss function to include a penalty on the variance of the interest rate. The idea is that with a large enough weight on the auxiliary term, the probability that interest rate fluctuations ever breach the zero floor is small. ${ }^{12}$ In this exercise I select a value for the weight on interest rate variability just sufficient to ensure that the counterfactual series under commitment is nonnegative over the sample period. ${ }^{13}$ The results are illustrated in Figure 6.

The interest rate path would still have been lower than the actual series during most of the 1980s, although the pace of monetary easing would have been slower under a zero bound constraint. The simulated data bottoms out at 3.80 percent in 1988:Q1 but stays near historical levels throughout the 1990s. Rates would have declined more gradually after 2000:Q4, but they also would have remained low after the Fed began to tighten policy in

\footnotetext{
${ }^{12}$ Eggertsson and Woodford (2003) and Adam and Billi (2007) study optimal monetary policy subject to the restriction that the interest rate be nonnegative in every state. Replacing this exact constraint with an alternative one on interest rate variability allows one to conserve the linear-quadratic setup of the model.

${ }^{13} \mathrm{~A}$ value of $\lambda_{i}=0.0024$ in a loss function of the form $E_{0}(1-\delta) \sum_{t=0}^{\infty} \delta^{t}\left\{\pi_{t}^{2}+\lambda_{y} y_{t}^{2}+\lambda_{\Delta i}\left(i_{t}-i_{t-1}\right)^{2}+\lambda_{i} i_{t}^{2}\right\}$ guarantees a strictly positive counterfactual sequence of nominal interest rates.
} 
2004:Q1. The largest gap between the counterfactual and observed series is 3.76 percentage points, occurring in 2002:Q4. Not surprisingly, the paths of inflation and the output gap would have been even closer to their historical counterparts had policy accounted for the zero bound. The biggest differences in the inflation and output gap series are 0.48 and 0.73 percentage points, respectively (1990:Q3 and 2004:Q4).

Panel B of Table 4 shows how these outcomes translate into policy loss. Moving from discretion to commitment while respecting the zero bound generates even smaller reductions in the variances of inflation and the output gap than what is reported in panel A. It also lowers the variance of the interest rate in first differences but increases it in levels. Loss under discretion is about 6 percent higher than commitment, yielding an inflation equivalent of only 0.3665 percentage points or an output gap equivalent of 1.1665 percentage points.

\section{Conclusion}

In this paper I estimate a new-Keynesian model of the US economy subject to the restriction that monetary policy minimizes the central bank's loss function. The forward-looking nature of the model draws a distinction between two modes of optimization, termed commitment and discretion. Using quarterly data over the Volcker-Greenspan-Bernanke era, I estimate the model separately under each policy. The goal is to judge which form of central bank optimization fits the data better and to determine the extent to which the two procedures generate different estimates of the model parameters, particularly the loss function weights.

Maximum likelihood estimates point to broad similarities in the parameters across policies with one major exception. The weight on interest rate smoothing is large under commitment but small under discretion. The result can be traced to the fact that commitment increases the volatility of the interest rate, and maximum likelihood tries to offset this effect by lifting the weight on policy smoothing. Measures of fit based on the likelihood function indicate 
that discretionary policy provides a superior description of the joint time series properties of the data. Additional evidence in favor of discretion can be drawn from comparisons of the standard deviations and autocorrelation functions implied by the two models.

The empirical analysis is carried out using a strictly binary framework in which the policy choices are either full commitment or discretion. It might be more realistic, however, to think about Fed behavior as lying somewhere between these two logical extremes. Schaumburg and Tambalotti (2007) develop a modeling device, which they call "quasi-commitment," that makes it possible to analyze a continuum of policies between commitment and discretion that differ in degree of credibility. In short, policymakers are understood by the public to renege on the optimal commitment plan every period with some constant probability. Outcomes converge to full commitment as this probability approaches zero and to discretion as it approaches unity. Using the quasi-commitment framework, it should be possible to estimate simultaneously the weights in the central bank's loss function and the exogenous probability that identifies it's measure of credibility. I plan to address this issue in future research. 


\section{References}

Adam, Klaus and Billi, Roberto M. "Discretionary Monetary Policy and the Zero Lower Bound on Nominal Interest Rates." Journal of Monetary Economics, April 2007, 54(3), pp. 728-52.

Barro, Robert J. and Gordon, David B. "A Positive Theory of Monetary Policy in a Natural Rate Model." Journal of Political Economy, August 1983, 91(4), pp. 589-610.

Bernanke, Ben S. and Mishkin, Frederic S. "Inflation Targeting: A New Framework for Monetary Policy?" The Journal of Economic Perspectives, Spring 1997, 11(2), pp. $97-116$.

Brock, William A.; Durlauf, Steven N. and West, Kenneth D. "Policy Evaluation in Uncertain Economic Environments." Brookings Papers on Economic Activity 1, 2003, 34, pp. 235-322.

Brainard, William C. "Uncertainty and the Effectiveness of Policy." American Economic Review, May 1967, 57(2), pp. 411-25.

Castelnuovo, Efrem. "The Fed's Preference for Policy Rate Smoothing: Overestimation due to Misspecification?" Topics in Macroeconomics, 2006, 6(2), Article 5.

Clarida, Richard; Galí, Jordi and Gertler, Mark. "The Science of Monetary Policy: A New Keynesian Perspective." Journal of Economic Literature, December 1999, 37(4), pp. 1661-707.

- "Monetary Policy Rules And Macroeconomic Stability: Evidence And Some Theory." The Quarterly Journal of Economics, February 2000, 115(1), pp. 147-80.

de Jong, Piet. "Smoothing and Interpolation with the State-Space Model." Journal of the American Statistical Association, December 1989, 84(408), pp. 1085-8.

Dennis, Richard. "Inferring Policy Objectives from Economic Outcomes." Oxford Bulletin of Economics and Statistics, September 2004, 66(S1), pp. 735-64.

. "The Policy Preferences of the US Federal Reserve." Journal of Applied Econometrics, January 2006, 21(1), pp. 55-77.

Dennis, Richard and Söderström, Ulf. "How Important Is Precommitment for Monetary Policy?" Journal of Money, Credit, and Banking, June 2006, 38(4), pp. 847-72.

Eggertsson, Gauti B. and Woodford, Michael. "The Zero Bound on Interest Rates and Optimal Monetary Policy." Brookings Papers on Economic Activity 1, 2003, 34, pp. 139-233. 
Favero, Carlo A. and Rovelli, Riccardo. "Macroeconomic Stability and the Preferences of the Fed: A Formal Analysis, 1961-96." Journal of Money, Credit, and Banking, August 2003, 35(4), pp. 545-56.

Fuhrer, Jeffrey C. "The (Un)Importance of Forward-Looking Behavior in Price Specifications." Journal of Money, Credit, and Banking, August 1997, 29(3), pp. 338-50.

- "Habit Formation in Consumption and its Implications for Monetary-Policy Models." American Economic Review, June 2000, 90(3), pp. 367-90.

Fuhrer, Jeffrey C. and Moore, George R. "Inflation Persistence." The Quarterly Journal of Economics, February 1995, 110(1), pp. 127-59.

Fuhrer, Jeffrey C. and Rudebusch, Glenn D. "Estimating the Euler Equation for Output." Journal of Monetary Economics, September 2004, 51(6), pp. 1133-53.

Galí, Jordi and Gertler, Mark. "Inflation Dynamics: A Structural Econometric Analysis." Journal of Monetary Economics, October 1999, 44(2), pp. 195-222.

Givens, Gregory E. and Salemi, Michael K. "Generalized Method of Moments and Inverse Control." Journal of Economic Dynamics and Control, October 2008, 32(10), pp. 3113-47.

Goodfriend, Marvin. "Inflation Targeting in the United States?" NBER Working Paper No. 9981, September 2003.

Hamilton, James D. Time Series Analysis. Princeton, NJ: Princeton University Press, 1994.

Ilbas, Pelin. "Estimation of Monetary Policy Preferences in a Forward-Looking Model: A Bayesian Approach." National Bank of Belgium Working Paper No. 129, March 2008a.

- "Revealing the Preferences of the US Federal Reserve." Catholic University of Leuven, mimeo, July 2008b.

Ingram, Beth Fisher; Kocherlakota, Narayana R. and Savin, N. E. "Explaining Business Cycles: A Multiple-Shock Approach." Journal of Monetary Economics, December 1994, 34(3), pp. 415-28.

Jensen, Henrik. "Targeting Nominal Income Growth or Inflation?" American Economic Review, September 2002, 92(4), pp. 928-56.

Kiley, Michael T. "A Quantitative Comparison of Sticky-Price and Sticky-Information Models of Price Setting." Journal of Money, Credit, and Banking, February 2007, 39(S1), pp. 101-25. 
Kydland, Finn E. and Prescott, Edward C. "Rules Rather than Discretion: The Inconsistency of Optimal Plans." Journal of Political Economy, June 1977, 85(3), pp. 473-91.

Levin, Andrew T. and Williams, John C. "Robust Monetary Policy with Competing Reference Models." Journal of Monetary Economics, July 2003, 50(5), pp. 945-75.

Lindé, Jesper. "Estimating New-Keynesian Phillips Curves: A Full Information Maximum Likelihood Approach." Journal of Monetary Economics, September 2005, 52(6), pp. 113549.

Lowe, Philip and Ellis, Luci. "The Smoothing of Official Interest Rates," in Philip Lowe, ed., Monetary Policy and Inflation Targeting. Reserve Bank of Australia, 1997, pp. 286312 .

McCallum, Bennett T. "Issues in the Design of Monetary Policy Rules." in John B. Taylor and Michael Woodford, eds., Handbook of Macroeconomics. Amsterdam: Elsevier, 1999, Volume 1, Part 3, pp. 1483-1530.

McCallum, Bennett T. and Nelson, Edward. "An Optimizing IS-LM Specification for Monetary Policy and Business Cycle Analysis." Journal of Money, Credit, and Banking, August 1999, 31(3), pp. 296-316.

Mishkin, Frederic S. "Monetary Policy and the Dual Mandate." Speech at Bridgewater College, Bridgewater, Virginia, April 2007.

Orphanides, Athanasios. "Monetary Policy Evaluation with Noisy Information." Journal of Monetary Economics, April 2003, 50(3), pp. 605-31.

Ozlale, Umit. "Price Stability vs. Output Stability: Tales of Federal Reserve Administrations." Journal of Economic Dynamics and Control, July 2003, 27(9), pp. 1595-610.

Roberts, John M. "How Well Does the New Keynesian Sticky-Price Model Fit the Data?" Contributions to Macroeconomics, 2005, 5(1), Article 10.

Rotemberg, Julio J. and Woodford, Michael. "An Optimization-Based Econometric Framework for the Evaluation of Monetary Policy," in Ben S. Bernanke and Julio J. Rotemberg, eds., NBER Macroeconomics Annual. Cambridge, MA: MIT Press, 1997, pp. 297-346.

Rudebusch, Glenn D. "Monetary Policy Inertia: Fact of Fiction?" International Journal of Central Banking, December 2006, 2(4), pp. 85-135.

Rudebusch, Glenn D. and Svensson, Lars E. O. "Policy Rules for Inflation Targeting," in John B. Taylor, ed., Monetary Policy Rules. Chicago and London: University of Chicago Press, 1999, pp. 203-46. 
Salemi, Michael K. "Econometric Policy Evaluation and Inverse Control," Journal of Money, Credit, and Banking, October 2006, 38(7), pp. 1737-64.

Schaumburg, Ernst and Tambalotti, Andrea. "An Investigation of the Gains from Commitment in Monetary Policy." Journal of Monetary Economics, March 2007, 54(2), pp. 302-24.

Smets, Frank and Wouters, Raf. "An Estimated Dynamic Stochastic General Equilibrium Model of the Euro Area." Journal of the European Economic Association, September 2003, 1(5), pp. 1123-75.

Söderlind, Paul. "Solution and Estimation of RE Macromodels With Optimal Policy." European Economic Review, April 1999, 43(4-6), pp. 813-23.

Söderström, Ulf; Söderlind, Paul and Vredin, Anders. "New-Keynesian Models and Monetary Policy: A Reexamination of the Stylized Facts." Scandinavian Journal of Economics, September 2005, 107(3), pp. 521-46.

Svensson, Lars E. O. "Inflation Targeting as a Monetary Policy Rule." Journal of Monetary Economics, June 1999, 43(3), pp. 607-54.

Taylor, John B. "Discretion Versus Policy Rules in Practice." Carnegie-Rochester Conference Series on Public Policy, December 1993, 39(1), pp. 195-214.

Woodford, Michael. "Inflation Stabilization and Welfare." Contributions to Macroeconomics, 2002, 2(1), Article 1.

- Interest and Prices: Foundations of a Theory of Monetary Policy. Princeton and Oxford: Princeton University Press, 2003a.

. "Optimal Interest-Rate Smoothing." Review of Economic Studies, October 2003b, 70(4), pp. 861-86. 
Figure 1: Vector Autocorrelation Functions
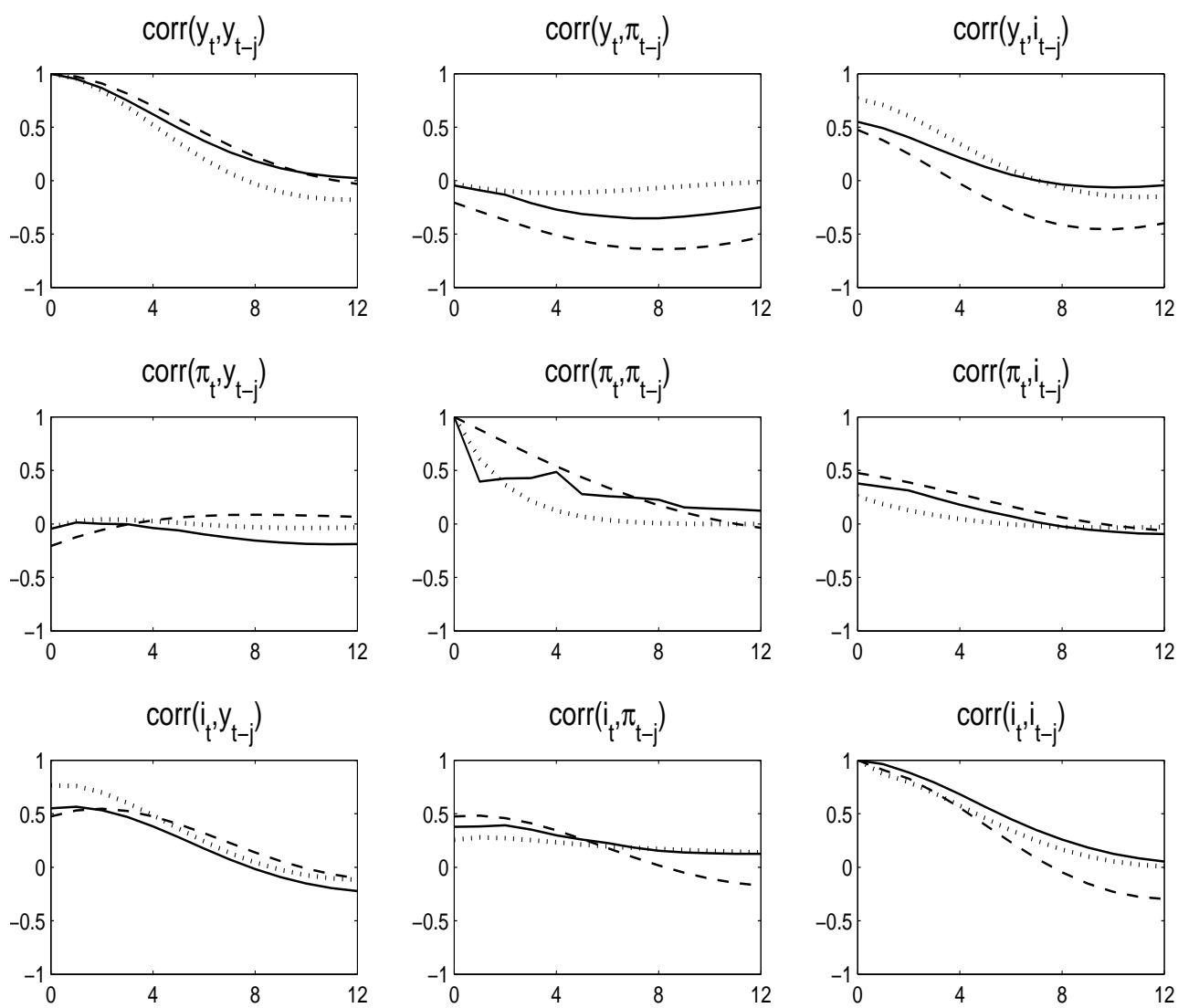

Notes: The figure shows the vector autocorrelation functions for the output gap $y$, inflation $\pi$, and the nominal interest rate $i$ implied by the US data (solid line), the estimated model under commitment (dashed line), and the estimated model under discretion (dotted line). 
Figure 2: Impulse Response Functions
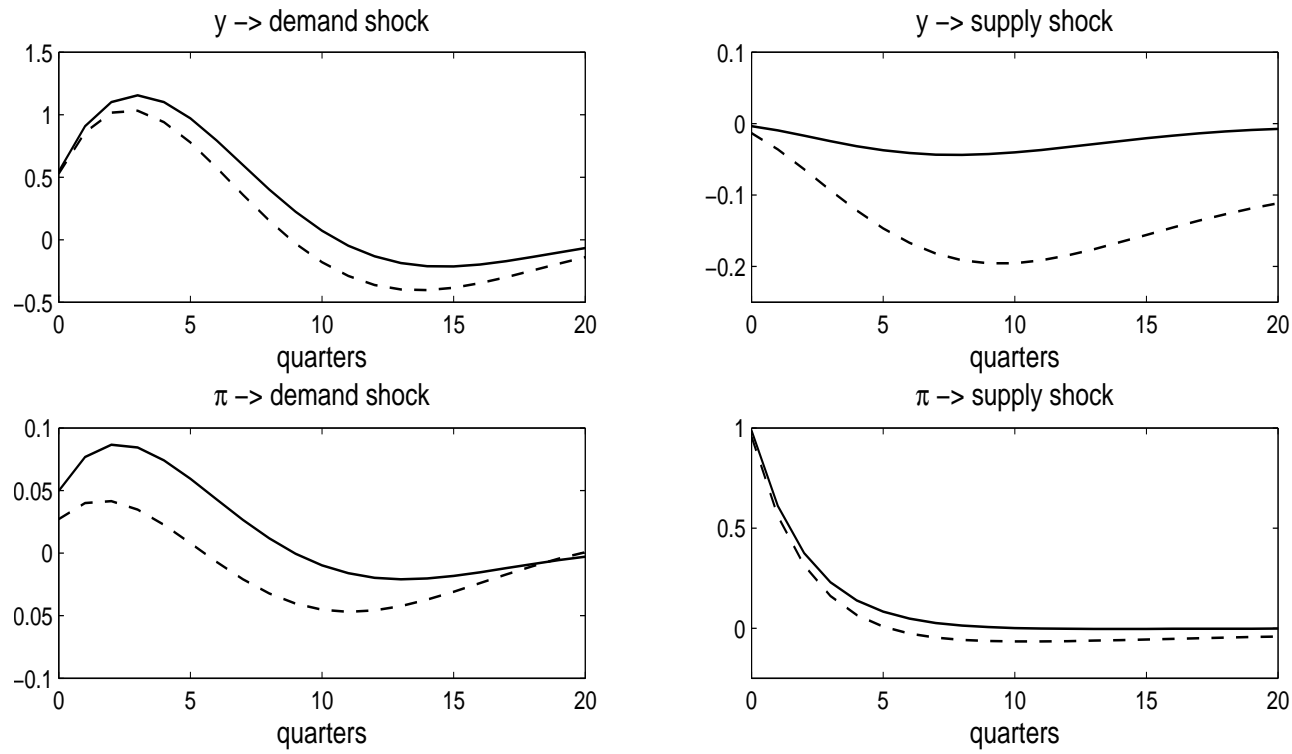

i $\rightarrow$ demand shock
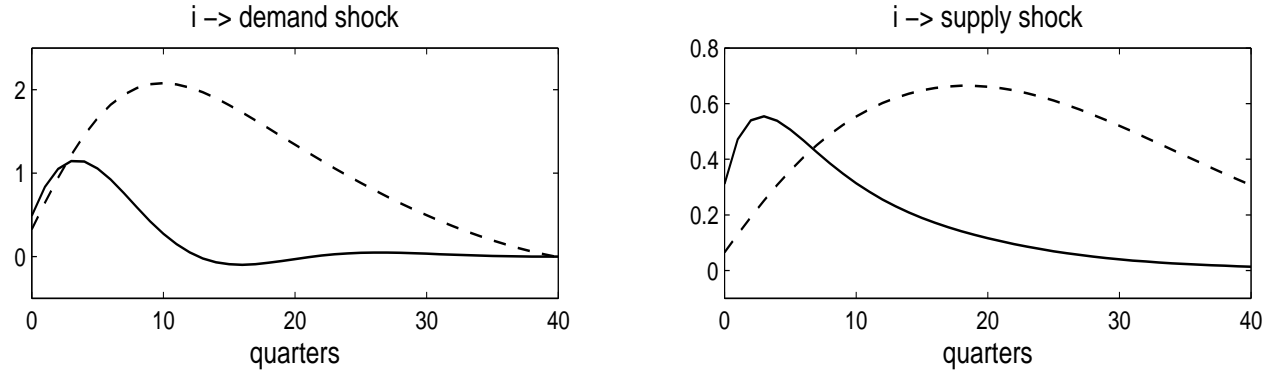

Notes: The figure displays the impulse responses of the output gap $y$, inflation $\pi$, and the nominal interest rate $i$ to a demand shock $u_{y, t}$ (left column) and a supply shock $u_{\pi, t}$ (right column). Response functions are graphed for the estimated model under discretion (solid line) and the commitment model using the same point estimates obtained under discretion (dashed line). Each panel traces out the effect of an estimated one standard deviation shock, and the values are interpreted as percent deviations from the steady state. 
Figure 3: Varying the Weight on Interest Rate Smoothing
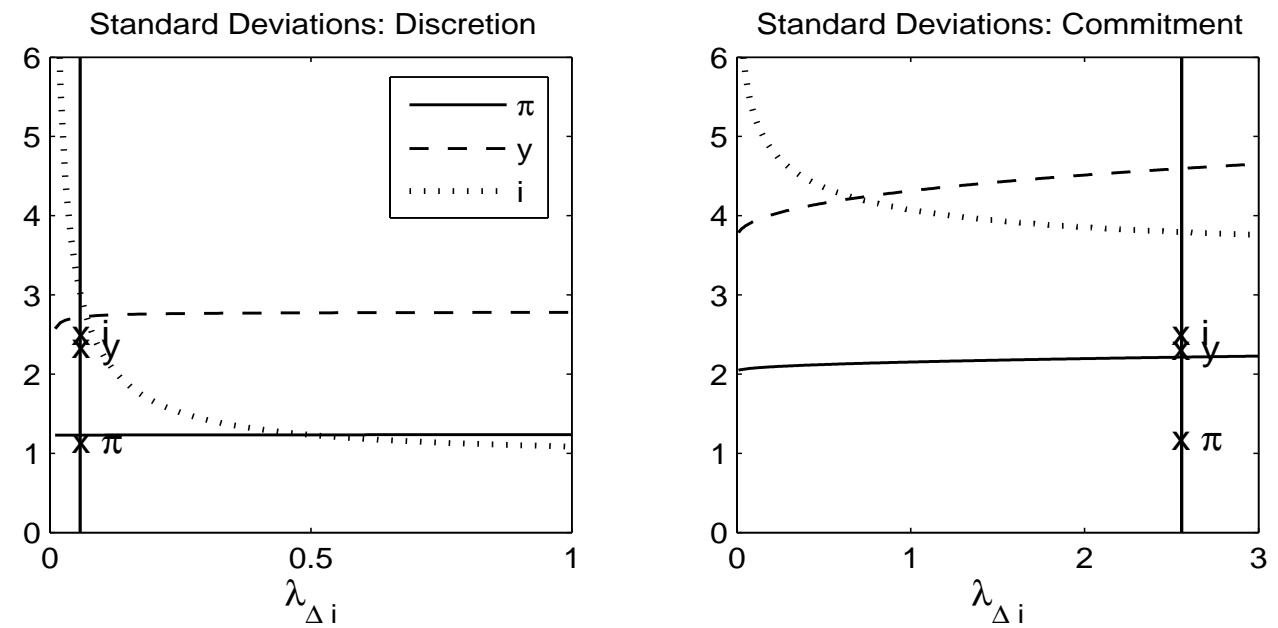

Notes: The figure displays the unconditional standard deviations of inflation (solid line), the output gap (dashed line), and the nominal interest rate (dotted line) as the weight on interest rate smoothing $\lambda_{\Delta i}$ varies from its estimated value, holding the other parameters fixed at their point estimates. The left panel graphs the functions implied by the estimated model under discretion. The right panel corresponds to commitment. Vertical lines indicate the estimated values of $\lambda_{\Delta i}$ and the crosses identify sample moments. 
Figure 4: Impulse Response Functions
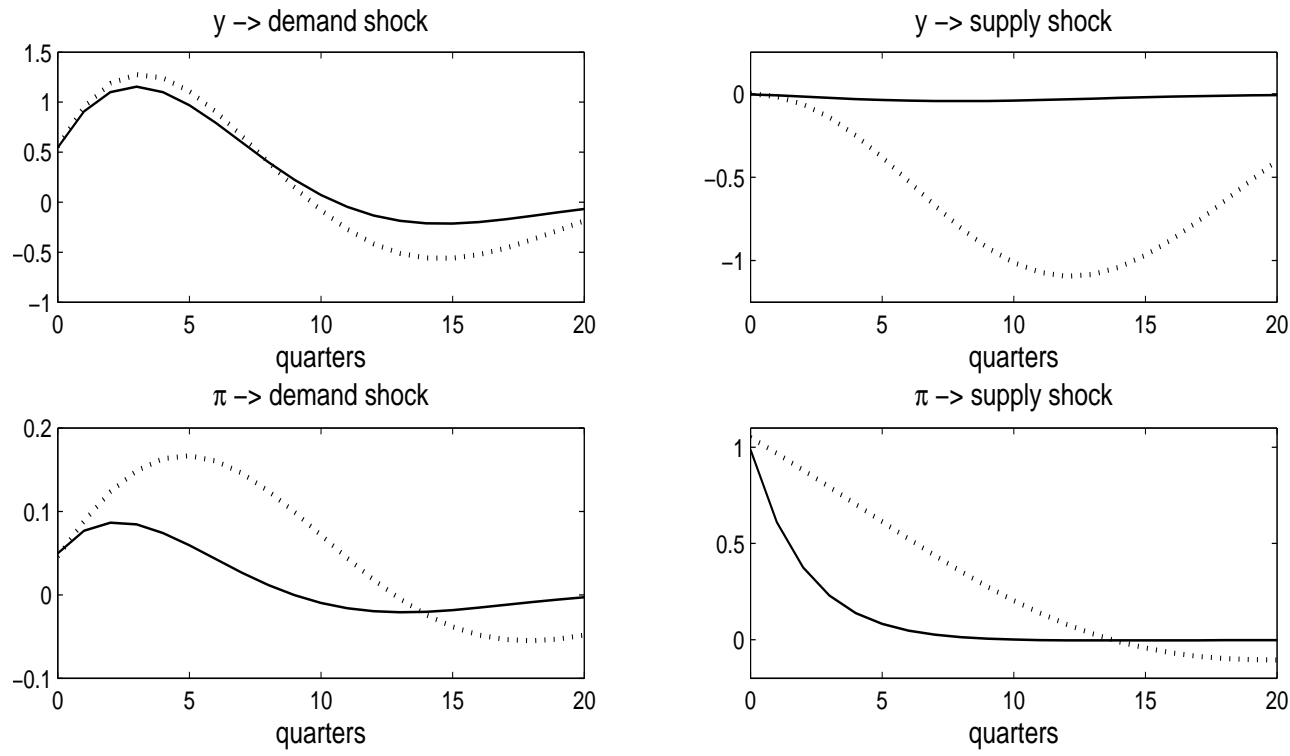

i $\rightarrow$ demand shock
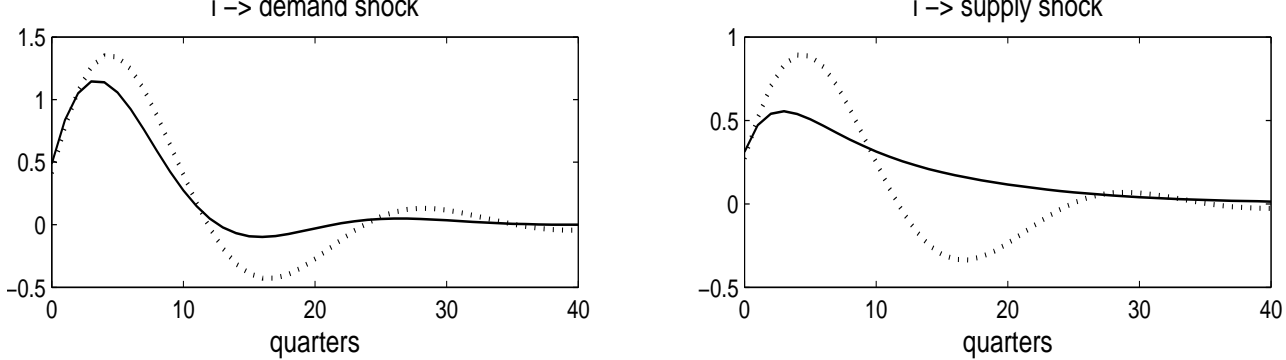

Notes: The figure displays the impulse responses of the output gap $y$, inflation $\pi$, and the nominal interest rate $i$ to a demand shock $u_{y, t}$ (left column) and a supply shock $u_{\pi, t}$ (right column). Response functions are graphed for the estimated model under discretion (solid line) and the estimated model under commitment (dotted line). Each panel traces out the effect of an estimated one standard deviation shock, and the values are interpreted as percent deviations from the steady state. 
Figure 5: Counterfactual Simulations
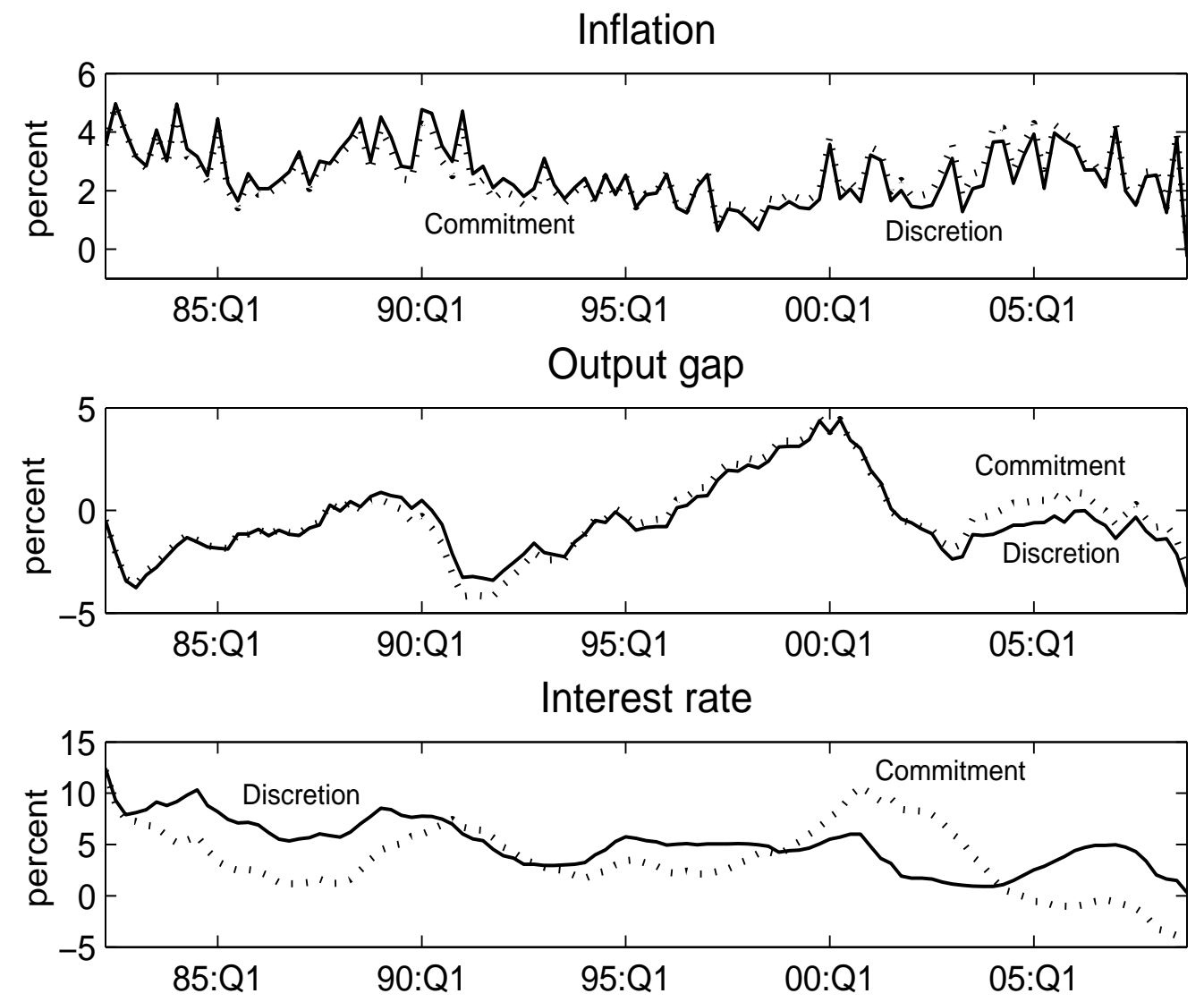

Notes: The figure plots the actual series driven by the estimated model under discretion (solid lines) and the counterfactual series generated under commitment (dotted lines). Counterfactual simulations are obtained by first estimating the sequence of historical shocks in the discretionary model using the fixed interval Kalman smoother. The shocks are then reinserted into the same model but with the central bank minimizing loss under commitment instead. 
Figure 6: Counterfactual Simulations with a Zero Bound Constraint
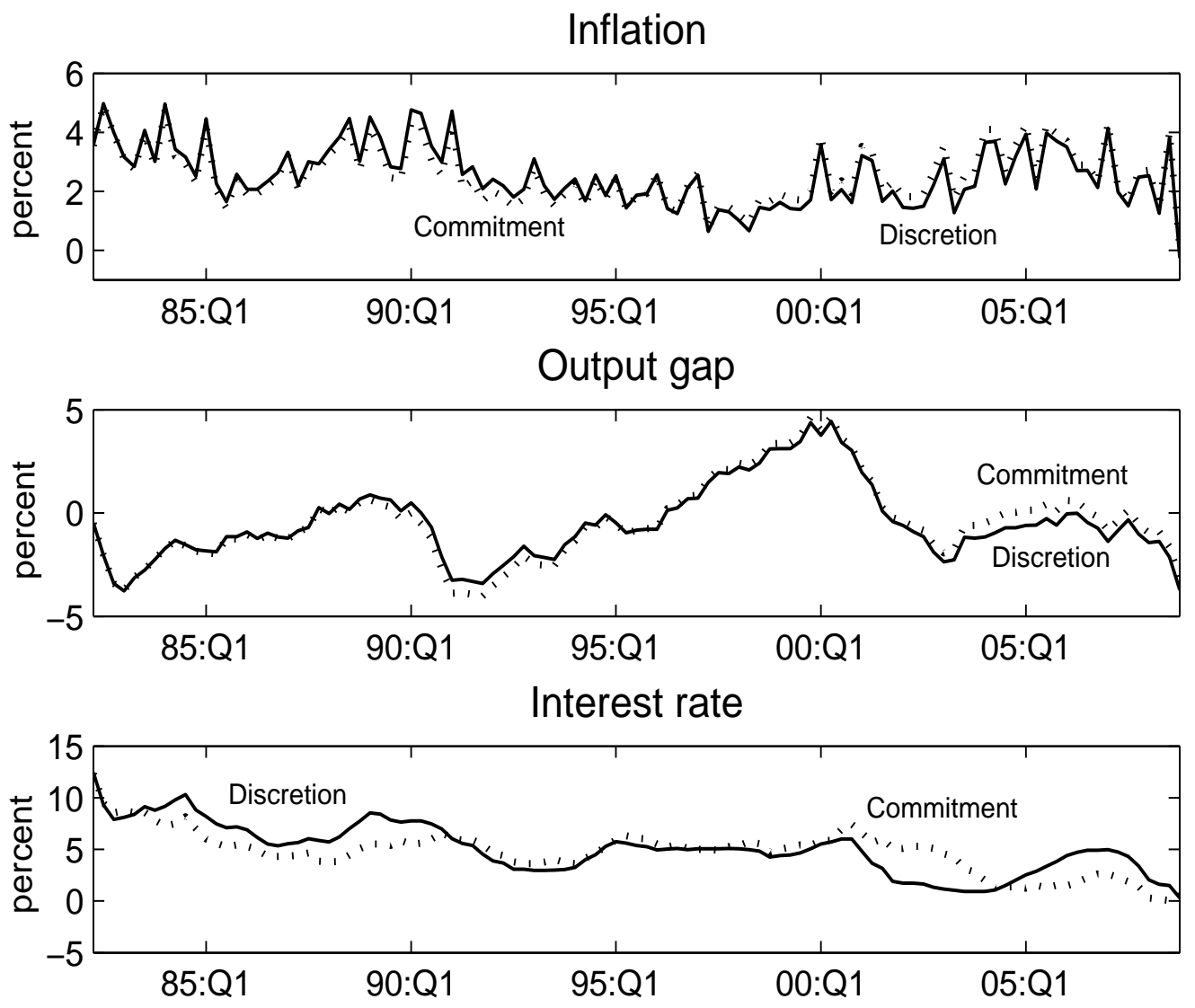

Notes: The figure plots the actual series driven by the estimated model under discretion (solid lines) and the counterfactual series generated under commitment (dotted lines) with the zero lower-bound restriction imposed on the nominal interest rate. Counterfactual simulations are obtained by first estimating the sequence of historical shocks in the discretionary model using the fixed interval Kalman smoother. The shocks are then reinserted into the same model but with the central bank minimizing loss under commitment instead. The loss function is amended to include a weight on the variance of the interest rate just large enough to ensure that the simulated path never violates the zero bound. 